\title{
Catalytic syntheses of silicon nanowires and silica nanotubes
}

\author{
Yi-Han Yang, Sheng-Jia Wu, Hei-Shan Chiu, Ping-I Lin and Yit-Tsong Chen \\ Department of Chemistry, National Taiwan University, Taipei 106, Taiwan, ROC and Institute of \\ Atomic and Molecular Sciences, Academia Sinica, P.O. Box 23-166, Taipei 106, Taiwan, ROC
}

\begin{abstract}
Silicon nanowires (SiNWs) have been fabricated with metal- and $\mathrm{SiO}_{2}$-catalyses assisted by laser ablation. In the growths of single-crystalline SiNWs by metal -catalysts, it is found that SiNWs are along <111 $>$ growth direction; however, the $<112>$ growth direction is resulted in the $\mathrm{SiO}_{2}$-catalyzed SiNWs. Pressure effect on the longitudinal and transverse growing rates of these SiNWs has also been examined. With the chemical vapor deposition method, the silica nanotubes $\left(\mathrm{SiO}_{2} \mathrm{NTs}\right)$ could be achieved with Au nanoparticles as catalysts. From electron diffraction pattern, it shows that the $\mathrm{SiO}_{2} \mathrm{NTs}$ are amorphous and the possible growth mechanism would be discussed.
\end{abstract}

Index Terms - chemical vapor deposition, growth mechanism, laser ablation, pressure effect, silica nanotubes, silicon nanowires, vapor-liquid-solid (VLS) growth.

\section{INTRODUCTION}

The optical and electrical properties of semiconductorbased nanostructures have recently stimulated tremendous research interest. A distinctive feature for semiconductorbased nanostructures relative to bulky material is the wellknown quantum confinement effect owing to the reduced size and/or dimensionality [1]. Silicon (Si) is an important semiconductor material with its contemporary microelectronic technology being one of the greatest successes for the past century. Nevertheless, there is still room for improvement in the applications of Si-based optoelectronic devices. The advance of nanotechnology has led a way to fabricate semiconductor materials from micro- to nano-meters in size. Among other developments, more and more syntheses for one-dimensional nanowires have been accomplished. For $\mathrm{Si}$, in particular, intensive research of one-dimensional nanowires and their corresponding optical and electrical properties have been studied by several groups. In the researches approached by these groups, the wirelike crystalline nanostructures of Si were often fabricated via vapor-liquid-solid (VLS) growth [2]. The sizes of the catalysts are considered to be responsible for diameters 'of the resultant silicon nanowires (SiNWs). Based on this correspondence, the application of laser ablation to vaporize a target sample of bulky $\mathrm{Si}$, mixed with metal catalyst, and to form small sizes of nanoclusters in the initial VLS process is a unique and quite powerful method in the fabrication of onedimensional SiNWs.

Besides the SiNWs for fabrication, the silica nanotubes $\left(\mathrm{SiO}_{2} \mathrm{NTs}\right)$ are also produced by the chemical vapor deposition method. Among the oxidic instances, particular focus has been put on nano-framed silica because of its potential applications as a catalyst support material [3], as a core material for biosensors and biomarkers [4], as storage/delivery containers for biochemical substances [5], and in optoelectronic nanodevice design [6]. Until now, most of the $\mathrm{SiO}_{2} \mathrm{NTs}$ are synthesized with the soft chemical methods.

Here, we will investigate the catalytic roles of different metal catalysts $\left(\mathrm{Fe}, \mathrm{Ru}, \mathrm{Pr}, \mathrm{RuCl}_{3}\right.$, and $\left.\mathrm{Pr}_{6} \mathrm{O}_{11}\right)$ and $\mathrm{SiO}_{2}$ in the syntheses of SiNWs assisted by laser ablation. From these comparisons, we have tried to discern the growth mechanism via $\mathrm{SiO}_{2}$-catalysis from that via the VLS in traditional metal-catalytic processes. Differences in the crystalline and wire growth axes of SiNWs have been examined for the $\mathrm{SiO}_{2^{-}}$and metal-catalytic SiNWs.

\section{EXPERIMENT}

The apparatus used in our catalytic-growth experiments assisted by laser ablation is described as follows. An evacuated alumina tube, placed inside a furnace, contains a target sample of Si powder and metal catalyst. We have used iron $(\mathrm{Fe})$, ruthenium $(\mathrm{Ru})$, praseodymium $(\mathrm{Pr})$, ruthenium chloride $\left(\mathrm{RuCl}_{3}\right)$, and praseodymium oxide $\left(\mathrm{Pr}_{6} \mathrm{O}_{11}\right)$ powders, respectively, as metal catalysts. Alternatively, $\mathrm{SiO}_{2}$ was regarded as another supplying source for $\mathrm{Si}$, and had also been introduced in the target sample. Totally, we have carried out six experiments, including $\mathrm{Si}+\mathrm{Fe}, \quad \mathrm{Si}+\mathrm{Ru}, \quad \mathrm{Si}+\mathrm{Pr}, \quad \mathrm{Si}+\mathrm{SiO}_{2}+\mathrm{Fe}$, $\mathrm{Si}+\mathrm{SiO}_{2}+\mathrm{RuCl}_{3}$, and $\mathrm{Si}+\mathrm{SiO}_{2}+\mathrm{Pr}_{6} \mathrm{O}_{11}$ as reacting ingredients, respectively. In the experiments without $\mathrm{SiO}_{2}$ in the target sample, Si powder and metal catalyst $(\mathrm{Fe}, \mathrm{Pr}$, or $\mathrm{Ru}$ ) were mixed with a weight ratio of $90: 10 \%$. When $\mathrm{SiO}_{2}$ was used in the growth of $\mathrm{SiNWs}$, the wt. ratio of $\mathrm{Si}$ : $\mathrm{SiO}_{2}$ : metal compound $\left(\mathrm{Fe}, \operatorname{Pr}_{6} \mathrm{O}_{11}\right.$, or $\left.\mathrm{RuCl}_{3}\right)$ was typically $45: 45: 10 \%$.

While in the $\mathrm{SiO}_{2}$ NTs case, a bubble bath container is placed with few amounts of $\mathrm{SiCl}_{4}(\sim 50 \mathrm{ml})$, which would 
TABLE I

Growth Direction, Composition, Crystallization, and Dimension of Catalytically Synthesized SiNWs

\begin{tabular}{|c|c|c|c|c|c|c|}
\hline & \multicolumn{6}{|c|}{ eacting ingredient } \\
\hline & $\mathrm{Si}+\mathrm{Fe}$ & $\mathrm{Si}+\mathrm{Ru}$ & $\mathrm{Si}+\mathrm{Pr}$ & $\mathrm{Si}+\mathrm{SiO}_{2}+\mathrm{Fe}^{\mathrm{a}}$ & $\mathrm{Si}+\mathrm{SiO}_{2}+\mathrm{RuCl}_{3}{ }^{\mathrm{b}}$ & $\mathrm{Si}+\mathrm{SiO}_{2}+\mathrm{Pr}_{6} \mathrm{O}_{11}{ }^{\mathrm{c}}$ \\
\hline Crystalline growth axis & {$[\overline{1} 1 \overline{1}]$} & [111] & $\overline{[111}]$ & {$[1 \overline{11}]$} & {$[\overline{1} \overline{1} 1]$} & [111] \\
\hline Wire growth axis & {$[\overline{111}]$} & {$[\overline{111}]$} & $\overline{[111]}$ & {$[112]$} & [112] & {$[\overline{112}]$} \\
\hline $\begin{array}{l}\text { Tip composition } \\
\text { Wire crystallization }\end{array}$ & $\begin{array}{l}\mathrm{FeSi}_{2} \\
\text { single }\end{array}$ & $\begin{array}{l}\mathrm{RuSi}_{3} \\
\text { single }\end{array}$ & $\begin{array}{c}\mathrm{PrSi}_{4} \\
\text { single }+ \text { poly }\end{array}$ & $\begin{array}{l}\mathrm{SiO}_{\mathrm{x}} \\
\text { single }\end{array}$ & $\begin{array}{l}\mathrm{SiO}_{x} \\
\text { single }\end{array}$ & $\begin{array}{l}\mathrm{SiO}_{\mathrm{x}} \\
\text { single }\end{array}$ \\
\hline Si core diameter & $\sim 36 \mathrm{~nm}$ & $\sim 5 \mathrm{~nm}$ & $\sim 16 \mathrm{~nm}$ & $\sim 8 \mathrm{~nm}$ & $\sim 5 \mathrm{~nm}$ & $\sim 15 \mathrm{~nm}$ \\
\hline $\mathrm{SiO}_{\mathrm{x}}$ sheath thickness & $\sim 5 \mathrm{~nm}$ & $\sim 9 \mathrm{~nm}$ & $\sim 3 \mathrm{~nm}$ & $\sim 9 \mathrm{~nm}$ & $\sim 10 \mathrm{~nm}$ & $\sim 5 \mathrm{~nm}$ \\
\hline \multicolumn{7}{|c|}{ 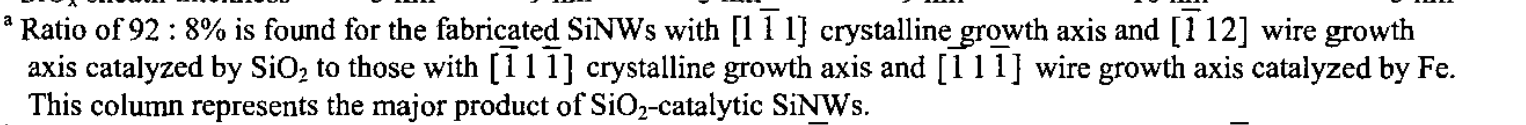 } \\
\hline \multicolumn{7}{|c|}{$\begin{array}{l}{ }^{b} \text { Ratio of } 92.3: 7.7 \% \text { is found for the fabricated SiNWs with }\left[\begin{array}{ll}1 & 1\end{array}\right] \text { crystalline growth axis and }[\overline{1} 12] \text { wire growth } \\
\text { axis catalyzed by } \mathrm{SiO}_{2} \text { to those with }\left[\begin{array}{ll}1 & 1\end{array}\right] \text { crystalline growth axis and }\left[\begin{array}{l}1 \\
1\end{array}\right] \text { wire growth axis catalyzed by } \\
\mathrm{RuCl}_{3} \text {. This column represents the major product of } \mathrm{SiO}_{2} \text {-catalytic SiNWs. }\end{array}$} \\
\hline \multicolumn{7}{|c|}{ 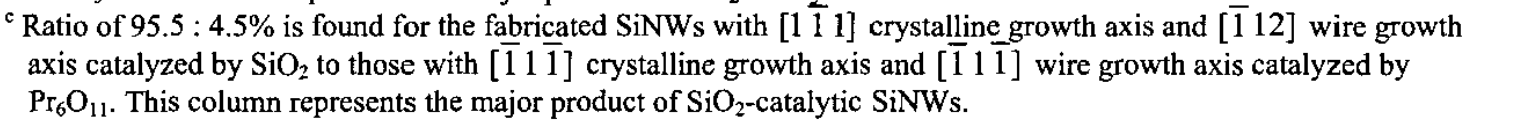 } \\
\hline
\end{tabular}

be the source material of the reaction. The carrier gas used here is the hydrogen gas, and with controlled for its flowing rate of $\sim 750 \mathrm{sccm}$. With the bubbled system, the $\mathrm{SiCl}_{4}$ is carried out by the carrier gas and goes into the reaction chamber under the heating of furnace. The temperature for reaction used for $\mathrm{SiO}_{2} \mathrm{NT}$ s synthesis is about $650^{\circ} \mathrm{C}$ in the center, and while the vapor from the bubbled system would start to deposit onto the silicon substrate, which is coated with a thin layer $(\sim 10-20 \mathrm{~nm})$ of $\mathrm{Au}$. Each experiment for $\mathrm{SiO}_{2} \mathrm{NTs}$ reaction is $\sim 20$ mins and keeps the chamber pressure of $\sim 100$ TorT, and then the chamber is vacuumed to about $30 \mathrm{mT}$ Torr to pump out the reaction species. When the temperature decreases to room temperature, the silicon substrate can be taken out and a very light white color can be seen on the silicon substrate.

\section{RESULTS AND DISCUSSION}

\section{A. Silicon Nanowires Synthesis}

As previous saying, the fabrication of SiNWs can be divided into six groups for discussion. In the $\mathrm{Fe}$ group $\left(\mathrm{Si}+\mathrm{SiO}_{2}+\mathrm{Fe}, \mathrm{Si}+\mathrm{Fe}\right)$, it could be first found that the wire growth directions of the two catalysts are very different. According to high-resolution transmission electron microscopy (HRTEM) images, the wire growth direction of $\mathrm{SiO}_{2}$-catalytic $\mathrm{SiNW}$ is $[\overline{1} 12]$ while it becomes to [111] in the pure Fe-catalyzed SiNWs case (Fig. la and 1b).
Such observation would be also investigated in the others, $\mathrm{Ru}$ (Fig. 1c and 1d) and Pr (Fig. 1e and 1f) groups, that the wire growth axis would be $\langle 112\rangle$ in $\mathrm{SiO}_{2}$-supplied precursors but the $\langle 111>$ wire growth direction is formed in pure metal catalytic SiNWs.
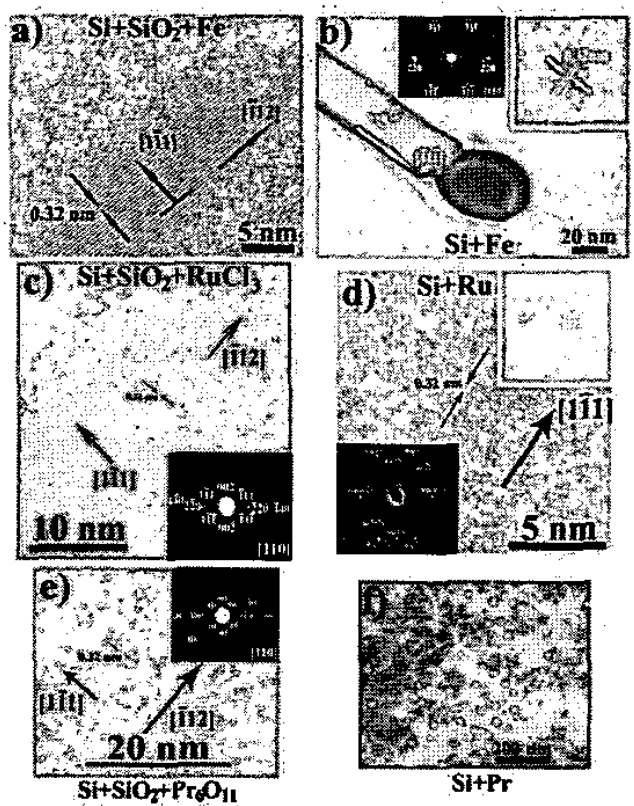

Fig. 1. (a) HRTEM image of the $\mathrm{SiO}_{2}$-catalytic SiNW showing the (1) lattice plane with d-spacing of $0.32 \mathrm{~nm}$ while the wire 
growth axis is $[\overline{1} 12]$. (b) HRTEM image of the Fe-catalytic SiNW, which indicates that the wire growth axis is [i11] . (c) HRTEM image of the $\mathrm{SiO}_{2}$-catalytic $\mathrm{SiNW}$ with the core diameter $\sim 5 \mathrm{~nm}$ shows the wire growth direction of [112]. (d) HRTEM image of the Ru-catalytic SiNW shows the crystalline (111) planes are parallel to the wire growth axis of [1/1]. (e) HRTEM image of the $\mathrm{SiO}_{2}$-catalytic $\mathrm{SiNW}$ shows the [112] wire growth direction. (f) SEM morphology of the Pr-catalytic SiNWs are with $\sim 30 \mathrm{~nm}$ of diameter and contain metal-tips (white spots), which provide the evidence of typical VLS growth mechanism.

Not only the wire growth directions are different, with detailed comparisons, it shows that the growth mechanism could be realized as two different models. For pure metalcatalyzed SiNWs, the tip composition shows that it forms silicides and could be believed the SiNWs follow the typical VLS process of growth. However, for $\mathrm{SiO}_{2}-$ catalytic SiNWs, such silicides composition could not be found. In the study of $\mathrm{Si}$ growth on $\mathrm{SiO}_{2}$ substrate by chemical vapor deposition, Dimitriadis et al. [7] found that an orientation filtering mechanism, due to the growthvelocity competition in the early stage of growth, it is responsible for the preferred orientation of Si films.

\section{B. Silica Nanotubes Synthesis}

The SEM and TEM morphologies of the CVD-grown $\mathrm{SiO}_{2} \mathrm{NT}$ s can be seen in Fig. 2. These $\mathrm{SiO}_{2} \mathrm{NT}$ s contains only the silicon and oxygen elements purely by EDS measurement and exist the ratio for $\mathrm{Si}: \mathrm{O}=1: 2$, which means that the composition would be the $\mathrm{SiO}_{2}$ nanotubes. Furthermore, it is hard to find the Au-tip in the end of $\mathrm{SiO}_{2} \mathrm{NT}$ s in the SEM image, implying that these $\mathrm{SiO}_{2} \mathrm{NT}$ s would not grow via the "tip growth" for normal VLS mechanism. Another important point here is that the sheaths of these $\mathrm{SiO}_{2} \mathrm{NT}$ s are so heavy for its thickness, and almost equal sizes for both the sheaths and tube channels.

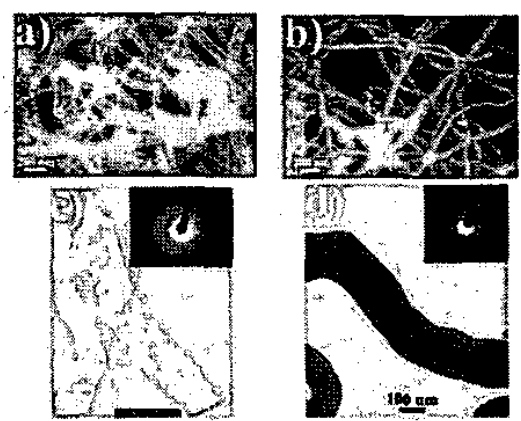

Fig. 2. (a) SEM image of $\mathrm{SiO}_{2} \mathrm{NTs}$, which are with uniform diameter of 40-60 nm and the length could extend to tens of $\mu \mathrm{m}$. (b) SEM morphology of $\mathrm{SiO}_{2} \mathrm{NTs}$ with thin thickness of sheaths $(\sim 10-20 \mathrm{~nm})$ compared with $\sim 30-80 \mathrm{~nm}$ of core diameter. (c) TEM image of the $\mathrm{SiO}_{2} \mathrm{NT}$ s with thick sheaths, showing that the core and sheath diameters are almost with equal sizes. (d) TEM morphology of the thick-sheath $\mathrm{SiO}_{2}$ NTs. A catalytic Au tip is contained with "polygonal" shape and with further check is found that the $\mathrm{SiO}_{2}$ sheath species are diffused from the Au tip and run out from the $\mathrm{Au}\{111\}$ facets to form the $\mathrm{SiO}_{2} \mathrm{NTs}$.

\section{CONCLUSION}

The growths of crystalline SiNWs with the catalyses of pure metals (Fe, $\mathrm{Ru}$, and $\mathrm{Pr}$ ) and $\mathrm{SiO}_{2}$. $\mathrm{Si}\{111\}$ planes have been found to be most stable in these catalytic fabrications. While the wire growth axis is along $<111\rangle$ for the pure metal-catalytic SiNWs complying with VLS mechanism, the wire growth axis directs to $<112>$ in the $\mathrm{SiNWs}$ catalyzed by $\mathrm{SiO}_{2}$. Under the chemical vapor deposition process, the amorphous $\mathrm{SiO}_{2} \mathrm{NTs}$ can be formed by the diffusion from the Au\{111\} facets.

\section{ACKNOWLEDGEMENT}

The electron microscopy measurements for this study in Instrumentation Centers of National Taiwan University and National Tsing-Hua University are acknowledged.

\section{REFERENCES}

[1] A. P. Alivisatos, "Semiconductor clusters, nanocrystals, and quantum dots" Science, vol. 271, pp. 933-937, February 1996.

[2] R. S. Wagner, and W. C. Ellis, "Vapor-liquid-solid mechanism of single crystal growth" Appl. Phys. Lett., vol. 4, pp. 89-90, March 1964.

[3] Y. Konishi, M. Okazaki, K. Toriyama, and T. Kasai, "Nanotube effect on a liquid-phase photoreaction in mesoporous silica“ J. Phys. Chem. B, vol. 105, pp. 9101 . 9106, October 2001.

[4] M. Quobosheane, S. Santra, P. Zhang, and W. Tan, "Biochemically functionalized silica nanoparticles" Analyst, vol. 126, pp. 1274-1278, August 2001.

[5] T. K. Jain, I. Roy, T. K. De, and A. Maitra, "Nanometer silica particles encapsulating active compounds: a novel ceramic drug carrier" J. Am. Chem. Soc., vol. 120, pp. 11092-11095, November 1998.

[6] H. J. Chang, Y. F. Chen, H. P. Lin, C. Y. Mou, "Strong visible photoluminescence from $\mathrm{SiO}_{2}$ nanotubes at room temperature" Appl. Phys. Lett., vol. 78, pp. 3791-3793, June 2001.

[7] C. A. Dimitriadis, J. Stoemenos, P. A. Coxon, S. Friligkos, J. Antonopoulos, and N. A. Economou, "Effect of pressure on the growth of crystallites of low-pressure chemicalvapor-deposited polycrystalline silicon films and the effective electron mobility under high normal field in thinfilm transistors" J. Appl. Phys., vol. 73, pp. 8402-8411, June 1993. 